\title{
Distribution and Antifungal Sensitivity of Candida Isolates Detected in Blood Cultures
}

\section{öz}

Kandidemi mortalite ile sonuçlanabilen ciddi bir klinik tablodur. Bu tablo özellikle yoğun bakım hastalarında sık görülmektedir. Bu retrospektif çalışmada, kan kültürlerinden izole edilmiş Candida suşlarının tanımlanması ve antifungal duyarlıık paternlerinin belirlenmesi amaçlanmıştır. Bu amaçla izole edilen Candida türleri identifiye edilmiş; amfoterisin B, kaspofungin, flusitozin, flukonazol, mikafungin ve vorikonazole duyarlılıkları araştırılmıştır. Ocak 2014-Aralık 2018 tarihlerinde kan kültürlerinden izole edilen Candida suşlarına Gram boyama ve germ tüp testi uygulanmış, Candida türlerinin tanımlanması ve antifungal duyarlılığının tespitinde VITEK 2 otomatize sistem kullanılmıştır. Candida spp. en sık yoğun bakım ünitelerinde ( $n=157, \% 64,9)$ saptanmış, bunu dahili servisler ( $n=64, \% 26,5)$ ve cerrahi servisler $(n=21, \%$ 8,6) izlemiştir. En sık izole edilen türler Candida albicans (100/242, \% 41,3) ve Candida parapsilosis'tir (92/242, \% 38). Özellikle yoğun bakım hastalarında, Candida türlerinin hızla tanımlanması ve antifungal duyarlılıklarının tespit edilmesi, tedavi planlaması için önemlidir. Bölgesel direnç durumunu yansıtan verilerin belli aralarla toplanmasının tedavi yaklaşımları açısından yol gösterici olacağı düşünülmektedir.

Anahtar kelimeler: antifungal duyarlılı, Candida, kan kültürü, kandidemi

\section{ABSTRACT}

Candidemia is a serious clinical condition that can result in mortality. This condition is particularly common in intensive care patients. This retrospective study aimed to identify Candida strains isolated from blood cultures and to determine antifungal susceptibility patterns. For this purpose, isolated Candida species were identified and, their susceptibility to amphotericin B, caspofungin, flucytosine, fluconazole, micafungin and voriconazole were investigated. VITEK 2 automated system was used to identify and detect antifungal susceptibility of Candida species that were subjected to Gram staining and germ tube tests on Candida species detected from blood cultures sent to our laboratory between January 2014 and December 2018. Candida spp. isolation rate was found most frequently ( $n=157 ; 64.9 \%$ ) in intensive care units; followed by internal clinics ( $n=64 ; 26.5 \%)$ and surgical clinics ( $n=21 ; 8.6 \%)$. The most frequently isolated species among these Candida isolates are Candida albicans (100/242; $41.3 \%)$ and Candida parapsilosis (92/242; $38 \%$ ). Especially in intensive care patients, rapid identification of Candida species and determination of their antifungal susceptibilities are important for planning treatment. It is thought that collecting data reflecting regional resistance status at certain intervals will be guiding in terms of treatment approaches.

Keywords: antifungal susceptibility, blood culture, Candida, candidemia
Received/Geliş: 03.06 .2020 Accepted/Kabul: 07.09.2020

Published Online/Online Yayın: 31.12.2020

Atıf/Cite as: Beder D, Esenkaya Taşbent F, Doğan M. Kan kültürlerinde tespit edilen Candida izolatlarının dağıımı ve antifungal duyarlııkları. ANKEM Derg. 2020;34(3):77-85.

Fatma Esenkaya Taşbent Necmettin Erbakan Üniversitesi Meram Tıp Fakültesi Tıbbi Mikrobiyoloji Anabilim Dalı Konya - Türkiye fesentas@hotmail.com ORCID: 0000-0003-4190-5095

D. Beder 0000-0001-5647-8458 M. Doğan 0000-0003-3471-4768 Necmettin Erbakan Üniversitesi Meram Tıp Fakültesi Tıbbi Mikrobiyoloji Anabilim Dalı Konya - Türkiye 


\section{Giriş}

Candida türleri deri, mukoza, gastrointestinal sistem ve vajende normal flora elemanı olmakla birlikte aynı zamanda önemli fırsatçı enfeksiyon etkenlerindendir. Geçmişte genellikle immünsupresif tedavi alan hastalarda görülen Candida'lar, günümüzde farklı hasta gruplarında giderek artan oranlarda bildirilmektedir ${ }^{(16,20,22)}$. Candida, özellikle yoğun bakım servislerinde yatan hastalarda önemli bir enfeksiyon etkenidir. Kan kültürlerinde tespit edilen en sık kandidemi etkeni Candida albicans olmasına rağmen, albicans-dışı Candida'ların sıklığı da her geçen gün artmaktadır ${ }^{(1,33,36)}$.

Candida enfeksiyonuna yol açan en sık risk faktörleri hastanın antibiyotik kullanma hikayesi, kan transfüzyonu yapılması, total parenteral beslenme ve üretral kateter varlığı olarak belirtilmektedir ${ }^{(42)}$. İnvaziv Candida enfeksiyonu görülme olasılığını artıran diğer faktörler ise solunum yollarına uygulanan tedavi ve hastanın kolonizasyon durumudur ${ }^{(1)}$. Hastalara uygulanan invaziv girişimlere bağlı olarak fırsatçı mantar enfeksiyonları artmaktadır. Bununla birlikte son yıllarda tedavide kullanılan antifungallerin direnç durumunda da önemli değiş̧iklikler meydana gelmiştir(6).

Flukonazol, triazol grubuna ait, etkili, maliyeti düşük bir antifungal ajan olup, maya kaynaklı enfeksiyonların tedavisinde sık kullanılmaktadır. Candida krusei flukonazole intrinsik dirençlidir ve flukonazolün Candida glabrata'ya karşı etkisi ise oldukça sınırlıdır ${ }^{(40)}$. Vorikonazol flukonazolden türetilen triazol grubu bir antifungal olup, sentetik yapıdadır ve geniş spektrum göstermektedir. Flukonazolün etkisinin sınırlı olduğu C.krusei ve C.glabrata türleri başta olmak üzere diğer Candida türlerine de etkilidir ${ }^{(37)}$.

Flusitozinin klinik kullanımı toksisitesi yüksek bir antifungal olması nedeniyle oldukça sınırlıdır ${ }^{(34)}$. Ekinokandinler kaspofungin, anidulafungin ve mikafunginden oluşan bir antifungal grubu olup, 1,3- $\beta$ D-glukan sentez inhibisyonu ile etki etmektedirler ${ }^{(39)}$. Bu glikol polimerleri memeli hücrelerinde görülmediğinden tedavi uygulanan hastalarda önemli bir hücreseltoksisiteyenedenolmazlar ${ }^{(24)}$. Ekinokandinler, son geliştirilen antifungal ilaçlardan olup, flukonazol dirençli suşlar ve Aspergillus türüne karşı bir miktar aktivite de dahil olmak üzere Candida türlerine karşı geniş spektrumda etki göstermektedirler ${ }^{(25)}$.

Hekimlerin hastane enfeksiyonlarını engellemeleri ve etkin bir tedavi uygulamaları için; sık görülen bu mikroorganizmaların direnç paternlerini ve zaman içindeki değişimlerini bilmeleri gerekir(12,36). Hastanelerde izole edilen Candida suşlarında antifungal direnç oranlarının belirlenmesi, ampirik tedavi planlamasına katkı sağlayacaktır ${ }^{(12,44)}$. Bu çalışmanın temel amacı enfeksiyon etkeni olan Candida türlerinin hastanemizdeki dağılımını tespit etmek ve hastane enfeksiyonlarının engellenmesine katkıda bulunmaktır.

\section{GEREÇ VE YÖNTEM}

Bu çalışmada, 2014-2018 tarihleri arasındaki beş yıllık süreçte üçüncü basamak bir üniversite hastanesi tıbbi mikrobiyoloji laboratuvarına gönderilen kan kültürlerinde tespit edilen 242 Candida izolatı araştırılmıştır. Retrospektif gerçekleştirilen bu çalışma, mikrobiyoloji laboratuvarının hastane kayıtları temel alınarak yapılmıştır. Aynı suş 18 hastadan iki kez, 7 hastadan üç kez, 3 hastadan ise 4 kez izole edilmiştir ancak bu hastaların ilk izolatı sonrası tekrarlayan suşları çalışmaya dahil edilmemiştir. Kan örnekleri otomatize kan kültür sistemi vasatlarına (BACTEC PLUS Aerobic/F, BACTEC 9120, $A B D)$ ekilip inkübe edilmiştir. Pediatrik popülasyon için BACTEC Peds Plus ve erişkin hasta grubu için BACTEC Plus aerobik besiyeri şişeleri kullanılmıştır. Bu besiyeri şişeleri 5-7 gün süreyle cihazda izlenmiş ve süre içerisinde pozitif sinyal veren kan kültürü örneklerinden Gram boyama yapılarak değerlendirilmiştir. Gram boyamada maya morfolojisinde görünen örnekler, Sabouraud dekstroz agar (SDA) ve \% 5 koyun kanlı agara ekim yapılarak $37^{\circ} \mathrm{C}$ 'de iki gün inkübe edilmiştir. Besiyerlerine yapılan ekimler ertesi gün değerlendirilmiş ve üreme olan örneklerden yeniden Gram boyama 
yapılmıştır. Gram boyama ile maya oldukları belirlenen mikroorganizmalara geleneksel mikolojik fenotipik yöntemlerden biri olan germ tüp testi yapılmıştır. SDA ve kanlı agar besiyerinde üreyen maya izolatları, VITEK 2 Compact System (bioMérieux, Fransa) kullanılarak identifiye edilmiş ve antifungal duyarlılıkları araştırılmıştır. Bu amaçla identifikasyon kartları (YST) ve antifungal duyarlılık kartları (AST-YSO8) kullanılmıştır. Böylece Candida izolatlarının amfoterisin B, kaspofungin, flusitozin, flukonazol, mikafungin ve vorikonazole karşı duyarlılıkları belirlenmiştir.

Bu duyarlılık yorumlamaları Candida parapsilosis, Candida tropicalis, C.tropicalis, C.glabrata ve C.krusei olarak tanımlanan beş tür için yapılmıştır. Sonuçlar Clinical Laboratory Standarts Institute (CLSI) kılavuzlarında antifungal ajanlar için belirlenen eşik değerlere göre değerlendirilmiştir. Candida izolatlarının amfoterisin B ve flusitozine karşı duyarlılıklarının belirlenmesinde CLSI M27-S3'te belirtilen sınır değerler kullanılırken; mikafungin, kaspofungin, flukonazol ve vorikonazole karşı duyarlılığın belirlenmesinde CLSI M27-S4'te belirtilen türe özgü sınır değerler kullanılmıştır ${ }^{(7,32)}$. Kullanılan antifungaller için minimum inhibitör konsantrasyon (MiK) değerleri; amfoterisin-B için $\leq 0,25 \mu \mathrm{g} / \mathrm{mL}$, kaspofungin için $\leq 0,25 \mu \mathrm{g} / \mathrm{mL}$, flukonazol için $\leq 1 \mu \mathrm{g} / \mathrm{mL}$, flusitozin için $\leq 1 \mu \mathrm{g} / \mathrm{mL}$, mikafungin için $\leq 0,06 \mu \mathrm{g} / \mathrm{mL}$ ve vorikonazol için $\leq 0,12$ $\mu \mathrm{g} / \mathrm{mL}$ 'dir.

Bu çalışma, Necmettin Erbakan Üniversitesi Meram Tıp Fakültesi İlaç ve Tıbbi Cihaz Dışı Araştırmalar Etik Kurulu onayı ile gerçekleştirilmiştir (22.11.2019/2170).

\section{BULGULAR}

Çalışmaya Ocak 2014-Aralık 2018 tarihleri arasında izole edilen 242 Candida suşu dahil edilmiştir. Suşların izole edildiği olguların 109'u (\% 45) kadın, 133'ü (\% 56) erkektir. Hastaların yaş dağılımına bakıldığında, 63'ü (\% 26) çocuk, 179’u (\% 74) ise erişkin hastalardan oluşmaktadır. İzole edilen farklı Candida türlerinin servislere göre dağılımı Tablo 1 'de verilmiştir. Sekiz olguda iki farklı Candida türü (5 olguda C.albicans ve C.parapsilosis, bir olguda Candida lusitaniae ve C.parapsilosis, bir olguda C.albicans ve Candida dubliniensis, bir olguda C.parapsilosis ve C.tropicalis), bir olguda üç farklı Candida türü (C.albicans, C.parapsilosis ve C.tropicalis) tespit edilmiştir. Çalışmaya alınan Candida türlerinin \% 64,9'u yoğun bakım ünitelerinden izole edilmiş olup, yoğun bakım ünitelerinde C.parapsilosis'in C.albicans'tan daha sık izole edilmesi dikkati çekicidir (Tablo 1).

Çalışmada C.albicans, C.parapsilosis, C.tropicalis, C.glabrata ve C.krusei izolatlarını içeren 221 suş için antifungal duyarlılık araştırılmış ve sonuçlar Tablo 2'de özetlenmiştir.

Çalışmada izole edilen tüm Candida türlerinin \% 78'i 18 yaş ve üzeri erişkin hastalara ait iken, \% 22'sini 18 yaş altı hastalar oluşturmaktadır. İzole edilen türlerin yaş gruplarına göre dağılımı Tablo 3'de sunulmuştur.

\section{TARTIŞMA}

Önemli bir morbidite ve mortalite sebebi olan

Tablo 1. İzole edilen Candida türlerinin klinik bölümlere göre dağııımı [n (\%)].

\begin{tabular}{lccc}
\hline & Yoğun Bakım Üniteleri & Dahili Servisler & Cerrahi Servisler \\
\hline C.albicans & $58(24)$ & $30(12,4)$ & $12(5)$ \\
C.parapsilosis & $72(29,8)$ & $16(6,6)$ & $4(1,6)$ \\
C.tropicalis & $10(4,1)$ & $2,5)$ & $2(0,8)$ \\
C.glabrata & $2(0,8)$ & $2(0,8)$ & - \\
C.krusei & $3(1,2)$ & $8(3,3)$ & $1(0,4)$ \\
* Diğer & $12(4,9)$ & $64(26,4)$ & $21(8,6)$ \\
\hline Toplam & $157(64,9)$ & & \\
\hline
\end{tabular}

${ }^{*}$ C.kefyr, C.spherica, C.dubliniensis, C.Iusitaniae, C.famata, C.guilliermondii, C.haemulonii, C.inconspicua), C.lipolytica, C.pelliculosa 
Tablo 2. İzole edilen Candida türlerinin antifungal duyarlılıkları [n (\%)].

\begin{tabular}{|c|c|c|c|c|c|c|c|c|c|c|c|c|c|c|c|}
\hline \multirow[b]{2}{*}{ Antifungal } & \multicolumn{3}{|c|}{ C.albicans } & \multicolumn{3}{|c|}{ C.parapsilosis } & \multicolumn{3}{|c|}{ C.tropicalis } & \multicolumn{3}{|c|}{ C.glabrata } & \multicolumn{3}{|c|}{ C.krusei } \\
\hline & S & DBD & $\mathbf{R}$ & S & DBD & $\mathbf{R}$ & $S$ & DBD & $\mathbf{R}$ & S & DBD & $\mathbf{R}$ & S & DBD & $\mathbf{R}$ \\
\hline Amfoterisin B & $92(92)$ & $3(3)$ & $5(5)$ & $89(96,7)$ & $2(2,1)$ & $1(1,1)$ & $16(100)$ & - & - & $8(100)$ & - & - & $4(80)$ & $1(20)$ & - \\
\hline Kaspofungin & $96(96)$ & $1(1)$ & $3(3)$ & $92(100)$ & - & - & $16(100)$ & - & - & $8(100)$ & - & - & $4(80)$ & $1(20)$ & - \\
\hline Flusitozin & 99 (99) & - & $1(1)$ & 92 (100) & - & - & $16(100)$ & - & - & $8(100)$ & - & - & $1(20)$ & $4(80)$ & - \\
\hline Flukonazol** & $87(87)$ & $4(4)$ & $9(9)$ & $86(93,5)$ & $1(1,1)$ & $5(5,4)$ & $15(93,8)$ & $1(6,2)$ & - & - & $8(100)$ & - & - & - & $5(100)$ \\
\hline Mikafungin & $97(97)$ & - & $3(3)$ & 91 (99) & $1(1,1)$ & - & $16(100)$ & - & - & $8(100)$ & - & - & $5(100)$ & - & - \\
\hline Vorikonazol & $93(93)$ & - & $7(7)$ & $89(96,7)$ & $2(2,1)$ & $1(1,1)$ & $16(100)$ & - & - & $8(100)$ & - & - & $5(100)$ & - & - \\
\hline
\end{tabular}

*S: Duyarlı, R: Dirençli, DBD: Doza Bağlı Duyarlı, **C.krusei flukonazole doğal dirençli

Tablo 3. İzole edilen Candida türlerinin yaş gruplarına göre dağılımı [n (\%)].

\begin{tabular}{|c|c|c|c|c|c|c|c|}
\hline & C.albicans & C.parapsilosis & C.tropicalis & C.glabrata & C.krusei & *Diğer & Toplam \\
\hline & $17(32)$ & $18(34)$ & $4(7,6)$ & $1(1,9)$ & $3(5,7)$ & $10(18,8)$ & $53(22)$ \\
\hline $\begin{array}{l}0-18 \text { yaş } \\
18 \text { yaş ve üzeri }\end{array}$ & $83(44)$ & $74(39,1)$ & $12(6,4)$ & $7(3,7)$ & $2(1)$ & $11(5,8)$ & $189(78)$ \\
\hline
\end{tabular}

${ }^{*}$ C.kefyr, C.spherica, C.dubliniensis, C.Iusitaniae, C.famata, C.guilliermondii, C.haemulonii, C.inconspicua, C.lipolytica, C.pelliculosa

kandidemilerde, mortalite oranları \% 20-30 arasında değişmektedir. Fırsatçı mikozlar, aynı zamanda hastanede yatış süresinin uzamasına ve maliyetin artmasına neden olmaktadır ${ }^{(8,43)}$. İnsanlarda görülen Candida enfeksiyonlarının \% 95'inden fazlasında etken olarak beş tür tespit edilmiştir. Bunlar C.albicans, C.parapsilosis, C.tropicalis, C.glabrata ve C.krusei'dir ${ }^{(13,38)}$.

Özellikle yoğun bakım ünitelerinde intravasküler kateter, endotrakeal entübasyon ve yoğun antibiyotik uygulamalarının kandidemiye neden olabileceği çeşitli çalışmalarda bildirilmektedir ${ }^{(12,45)}$. Trakya Üniversitesi Sağıı Araştırma ve Uygulama Merkezi'nde yapılan bir çalışmada kandidemi olgularının \% 34'ünü yoğun bakım servislerinde yatan hastaların oluşturduğu bildirilmiştir ${ }^{(22)}$. Erdem ve ark.'ları yaptıkları çalışmada invaziv Candida enfeksiyonu görülen hastaların \% 87,3’nün yoğun bakım ünitelerinde izlenen hastalar olduğunu tespit etmişlerdir(12). Yine bir başka çalışmada kandidemi olgularının \% 78'inin yoğun bakım servislerinde yatan hastalarda görüldüğü vurgulanmıştır(8). Bizim çalışmamızda ise kandidemi olgularının \% 64,9'u yoğun bakım servislerinde yatan hastalardır. Candida enfeksiyonunun yoğun bakım ünitelerinde yatan hastalarda görülme sıklığının daha fazla oluşunun, yatış süresinin uzama- sına paralel olarak artan invaziv işlemler nedeniyle doğal savunma sisteminin kırılmasına ve enfeksiyon oluşumuna zemin hazırlamasına bağlı olduğu düşünülmektedir. Görülen bu yüksek oranlar yoğun bakım servislerinde yatan hasta grubunun kandidemi oluşma riski açısından yakın takip edilmesinin önemini ortaya koymaktadır.

Çalışmamızda intravasküler kateter, hiperalimentasyon sıvıları ve prostetik materyaller ile bulaştığı bilinen C.parapsilosis'in yoğun bakım ünitelerinde yatan hastalarda en sık tespit edilen Candida türü olduğu ve albicans-dışı Candidalar arasında ise en sık saptanan tür olduğu görülmektedir. C.parapsilosis el florasında yer almaktadır ve biyofilm oluşturarak tıbbi aletlere kolayca tutunabilmektedir. Bu nedenle albicans-dışı Candida türleri arasında en fazla nozokomiyal enfeksiyona yol açan tür olduğu bildirilmektedir(28). Bu çalışmada yoğun bakım ünitelerinde C.parapsilosis'in, C.albicans'dan daha sık tespit edilmesi ile ilgili olarak; hastaların hastane içindeki transferleri, hastalar ve sağlık personelinin yol açtığı çapraz bulaşlar sonucu suşların hastane içerisinde kolayca yayıldığı ve buna bağlı olarak uzun süre varlığını sürdürdüğü tespit edilmiştir.

Candida türlerinin görülme sıklıkları ile ilgili ola- 
rak, farklı coğrafik bölgelere ve ülkelere göre farklı oranlar bildirilmektedir. Yurt dışında yapılan çalışmalarda, C.albicans'ın kan kültürlerinde en sık tespit edilen Candida türü olduğu ifade edilmekte, bazı çalışmalarda ise ilk sırayı C.parapsilosis almaktadır ${ }^{(26,41)}$. Candida'larla ilgili dünya geneli verileri analiz eden bir çalışmada en sık tespit edilen Candida türü Orta ve Kuzey Avrupa ve ABD'de C.albicans; Güney Avrupa, Asya ve Güney Amerika'da albicans-dışı Candidalar olarak bildirilmiştir ${ }^{(14)}$. Ülkemizden bildirilmiş kandidemi olgularında ise genellikle C.albicans birinci sırada, C.parapsilosis ise ikinci sırada bulunmuştur ${ }^{(8,13)}$.

Kan kültürlerinden yapılan bir çalışmada izole edilen 97 Candida suşunun \% 68'i C.albicans, kalan \% 32'lik kısmının ise başta C.parapsilosis (\% 14.5) olmak üzere albicans-dışı Candida olduğu bildirilmiştir(3). Grandesso ve ark. ${ }^{(15)}$ yaptıkları bir çalışmada kan kültürlerinden izole ettikleri Candida türlerinin \% 48'nin C.albicans, \% 23'nün C.parapsilosis olduğunu rapor etmişlerdir. Güney Kore'de yapılan bir başka çalışmada ${ }^{(19)}$ C.albicans \% 38, C.parapsilosis \% 26, C.tropicalis \% 20 olarak bulunmuştur. Öztürk ve ark. ${ }^{\left({ }^{30}\right)}$ kan kültürlerinde C.albicans' \% 53, C.parapsilosis'i \% 30, C.tropicalis'i \% 5,5 sıklıkta izole etmişlerdir. Şahiner ve ark. ${ }^{(36)}$ yaptıkları çalışmada ise Candida'nın etken olduğu hastane enfeksiyonlarında, C.parapsilosis \% 38,5, C.tropicalis \% 30,8 ve C.albicans \% 26,9 sıklıkta izole edilmiştir. Söz konusu çalışmada irdelenen suşların hastane enfeksiyonu etkeni olması ve bu suşlar arasında C.albicans'ın üçüncü sırada olup en sık izole edilen iki türün albicans-dışı Candida olması dikkat çekicidir. Günümüzde özellikle immünsüprese hastalardan izole edilen suşlarda, albicans-dışı Candida türlerinde artış görüldüğü birçok merkezden bildirilmektedir ${ }^{(17)}$. Albicans-dışı Candida türlerinin dağılımında birtakım farklııklar göze çarpmaktadır. Bazı araştırmacılar C.albicans'dan sonra ikinci sırada $C$. glabrata'nın olduğunu vurgularken, bazıları ise $C$. parapsilosis'in en sık tespit edilen albicans dışı Candida türü olduğunu ifade etmektedirler ${ }^{(12,21)}$. Erdem ve ark.'nın ${ }^{(12)}$ yaptığı çalışmada albicans dışı en sık saptanan Candida türü C.glabrata iken, C.parapsilosis Candida türleri arasında dördüncü sıklıkta bulunmuştur.

Bizim çalışmamızda tüm örnekler baz alındığında birbirine oransal olarak yakın olmakla birlikte en sık C.albicans, ikinci sırada C.parapsilosis tespit edilmiştir. Yoğun bakım hastalarında ise en sık etken C.parapsilosis iken, C.albicans ikinci sıklıktaki etken olarak bulunmuştur.

Çalışmamızda tespit edilen Candida türleri arasında C.pelliculosa, C.guilliermondii, C.haemulonii, C.inconspicua gibi nadir görülen türler de bulunmaktadır. Nadir etkenlerden olan Candida auris otomatize sistemlerde birçok tür ile karıştırabilmektedir. Genom analizleri C.auris'in; C.haemulonii, C. duobushaemulonii ve C.pseudohaemulonii ile genetik olarak yakınlığını tespit etmiştir(27). Bu sebeple C.auris, genellikle biyokimyasal testlerin kullanıldığı rutin tanı laboratuvarlarında, sıklıkla C.haemulonii olarak yanIıs raporlanabilmektedir. Bunun yanı sıra API AUX 20C, VITEK-2 YST, BD Phoenix, and MicroScan gibi biyokimyasal özellikleri temel alan ticari testlerde; C.famata, C.sake, Rhodotorula glutinis, R.mucilaginosa, Saccharomyces, C.catenulata, C.lusitaniae, C. guilliermondii ve C.parapsilosis gibi hatalı tanımlama sonucu verdiği bildirilmiştir. Matriks aracılı lazer dezorpsiyon iyonizasyon uçuş zamanı kütle spektrometresi (MALDI-TOF), C.auris'i diğer Candida türlerinden ayırt etmede güvenilirdir. Ancak, MALDI-TOF cihazlarının referans veri tabanlarının tümü bu ayrımı gerçekleştirememektedir. Ayrıca MALDI-TOF cihazı maliyeti nedeniyle birçok mikrobiyoloji laboratuvarında bulunmamaktadır ${ }^{(4)}$. Yine, 28s rDNA'nın D1-D2 bölgesinin veya rDNA'nın internal transkribe bölgesinin dizilimine dayanan polimeraz zincir reaksiyonu bazlı moleküler yöntemler doğru ve güvenilir sonuç verse de bu yöntemler maliyet etkin değildir ve rutin tanıda kullanılmamaktadır ${ }^{(18)}$. Nadir görülen bu türlerin sekans analizi veya önerilen MALDI TOF MS yöntemi ile tanımlanması, duyarlılıklarının belirlenmesi ve dirençli türlerin saptanması klinik olarak önem taşımaktadır. Ancak çalışmamız retrospektif bir çalışma olduğundan bu tanımlamalar yapılamamıştır ve 
bu durum çalışmanın kısıtııı̆ı̆ı oluşturmaktadır.

Antifungal duyarlılık testlerinde sıvı mikrodilüsyon yöntemi, CLSI ve European Committee on Antimicrobial Susceptibility Testing (EUCAST) tarafından belirlenmiş ve referans yöntem olarak kabul edilmişti ${ }^{r(8,31)}$. Sıvı mikrodilüsyon yöntemi ile doğrulamada, sonuçların raporlanması 48 saati bulabilmekte ve bu süre iş akışı yönünden birtakım problemlere yol açabilmektedir. Antifungal duyarlılık testlerinde tekrarlanabilirliğinin iyi olması ve bazı çalışmalarda CLSI’ın referans yöntem olarak belirttiği sıvı mikrodilüsyon yöntemiyle \% 90'dan fazla uyum göstermesi nedeniyle laboratuvarımızda rutin çalışmalarda VITEK 2 Compact $^{\circledR}$ otomatize sistem kullanılmaktadır ${ }^{(5)}$. Çalışmanın retrospektif bir çalışma olmasından dolayı, antibiyotik duyarlılıkları sıvı mikrodilüsyon ile doğrulanamamıştır.

Çalışmamızda sekiz olguda, iki farklı Candida türü, (5 olguda C.albicans-C.parapsilosis, 1 olguda C.Iusitaniae-C.parapsilosis, 1 olguda C.albicansC.dubliniensis, 1 olguda C.parapsilosis-C.tropicalis), bir olguda üç farklı Candida türü (C.albicansC.parapsilosis-C.tropicalis) tespit edilmiştir. Bourgeois ve ark.'nın yaptığı çalışmada ise hastaların \% 4,6'sında iki farklı tür Candida izole edilmiş olup, görülen polifungal infeksiyonlarda geniş spektrumlu antifungal tedavi gerekliliğinin önemi vurgulanmaktadır ${ }^{(5,13)}$.

Günümüzde kandidemi insidansında artış görülmekle birlikte Candida türlerinin sık kullanılan antifungal ajanlara karşı duyarlııklarında da birtakım değişiklikler meydana gelmiş ve direnç oranlarında belirgin artış tespit edilmiştir ${ }^{(21)}$. Bu nedenle tıbbi mikrobiyoloji laboratuvarlarında antifungal duyarlıık profilinin belirlenmesi tedavi seçimi ve enfeksiyon kontrolü açısından büyük önem taşımaktadır ${ }^{(13)}$. Son yıllarda Candida türlerinin sık rastlanan mikroorganizmalar olması, özellikle yoğun bakım servislerinde profilaktik antifungal kullanımına neden olmakta, bu durum antifungallere dirençli ya da orta derecede duyarlı suşların oluşmasına yol açmaktadır ${ }^{(8)}$. Fungal patojenlerin dirençli suşlarının görülme sıklığındaki bu artış, in vitro antifungal duyarlııı testlerine olan ihtiyacın artmasına neden olmuştur ${ }^{(12)}$.

Literatür verilerine bakıldığında antifungal direnç oranları ile ilgili olarak farklı merkezlerden farklı oranlar bildirilmiştir. Çalışmaların çoğunda amfoterisin B direnci ya tespit edilmemiş ya da birkaç suş için bildirilmiştir ${ }^{(2,9,29,30)}$. Bu çalışmada otomatize sistemle beş C.albicans ve bir C.parapsilosis suşunda amfoterisin B direnci tespit edilmiştir. Ancak bu suşların direncinin sıvı mikrodilüsyon yöntemi ile doğrulanması gerekmektedir. Çalışmamızla benzer olarak amfoterisin B direncini, Erdem ve ark. ${ }^{(12)} 114$ Candida suşunun $5^{\prime}$ inde $(\% 4,4)$ bildirirken, Savcı ve ark. ${ }^{(34)} 28$ C.albicans suşunun bir tanesinde (\% 3,5) raporlamışlardır. Antifungal duyarlııı̆ın sıvı mikrodilüsyonla bakıldığı yurt dışından bir çalışmada, 23 Candida suşundan 9'unda (\% 39,1) amfoterisin B direnci bulunmuştur. Amfoterisin B direnci olan bu dokuz suşun 7'si C.albicans, 2'si C.parapsilosis izolatı olarak bildirilmiştir ${ }^{(23)}$.

Çalışmamızda direnç oranı yüksek bulunan antifungallerden biri de flukonazol direncidir. Flukonazol direnci bu çalışmada C.albicans için \% 9, C.parapsilosis için \% 5,4 olarak bulunurken; C.glabrata'nın tüm suşları doza bağlı duyarlı bulunmuştur. Yenidoğanlarda yapılan 54 olguyu içeren bir çalışmada ${ }^{(2)}$ flukonazole direnç oranı \% 5,5 olarak tespit edilirken, Özbek ve ark.'nın ${ }^{(29)} 55$ Candida olgusunda yaptığı çalışmada \% 1,8, Çiçek ve ark.'nın ${ }^{(9)}$ kan kültüründen izole ettikleri 1238 Candida olgusunda \% 2,2, Erdem ve ark.'nın ${ }^{(12)} 114$ Candida olgusunda $\% 7$ oranında flukonazol direnci bildirilmiştir.

Ekinokandin grubu ilaçlara direnç ilk kez 2005 yılında tanımlanmış olup, referans yöntemlerle ekinokandinlerde direnç gelişimi nadirdir. Kolorimetrik mikrodilüsyon ile çalışılan bir çalışmada 102 Candida suşunun hiçbirinde ekinokandin direnci tespit edilmemiştir $^{(10)}$. Sütçü ve ark. ${ }^{(35)} 54$ Candida suşunda E test ile antifungal duyarlılık çalışmışlar ve bir C.parapsilosis suşunda kaspofungin direnci, bir C.Iusitaniae suşunda anidulafungin direnci bildirmişlerdir. Bir diğer çalışmada CLSI ve EUCAST sIVı mikrodilüsyon yöntemleri karşılaştırılmış ve C.albicans'ta CLSI SIVI mikrodilüsyon ile bir, EUCAST ile iki izolatta 
anidulafungin direnci tespit edilmiştir. Aynı çalışmada C.parapsilosis izolatlarının ikisinde EUCAST mikrodilüsyon ile anidulafungin direnci bulunmuştur ${ }^{(11)}$. Postmortem otopsi örneklerinden yapılan bir başka çalışmada VITEK 2 otomatize sistem ile Candida suşlarının hepsinde mikafungin direnci tespit edilmiştir ${ }^{(46)}$. Diğer yandan antifungal duyarlılığın sıvı mikrodilüsyonla çalışıldığı yurt dışı bir çalışmada, 23 Candida suşu arasında $4(\%$ 17,4) C.albicans izolatında kaspofungin direnci rapor edilmiştir ${ }^{(23)}$. Çalışmamızda ise C.albicans izolatlarının üçünde kaspofungin, üçünde mikafungin direnci bulunmuş olup, referans yöntemle doğrulanamamıştır. Araştıılan diğer antifungallerden vorikonazol direnci \% 3,5, flusitozin direnci \% 0,4 olarak bulunmuş olup genel olarak literatür verilerine yakındır. Direnç profilleri, alınan örnek türü ve kliniklere göre değişmektedir. Kandidemilerde ve yoğun bakımdan gelen örneklerde direnç oranlarının arttığı görülmektedir.

Bir diğer önemli husus ise direnç durumunun C.albicans ve albicans-dışı Candida'lardaki değişimidir. Çalışmamızda antifungallere direnç daha ziyade C.albicans suşlarında görülmüş, albicans-dışı Candida'larda direnç beklenenden düşük bulunmuştur. C.parapsilosis için ise, yoğun bakım ünitelerinden gelen örneklerin çoğu bu türe ait olmasına rağmen yalnız yedi C.parapsilosis suşunda antifungallerden en az birine direnç tespit edilirken, altı suşta da doza bağlı duyarlılık görülmüştür. Dirençli şuşlar ağırlıklı olarak yoğun bakım ünitelerinden gelen örneklerde tespit edilmiştir.

Sonuç olarak gerek yoğun bakım ünitelerinde, gerekse diğer dahili yada cerrahi klinik birimlerde ortaya çıkan Candida enfeksiyonlarının tedavisinde klinisyeni yönlendirecek bu tip çalışmaların her merkezde ve belli periyotlar ile yapılması büyük önem taşımaktadır. Candida enfeksiyonlarında tür identifikasyonu ve antifungal duyarlılık testleri, tanı ve etkene uygun erken tedavinin başlatılmasında yararlı olacaktır. Her merkezin kendi tür dağııımını ve direnç durumunu tespit etmesi ve yıllar içindeki değişimini izlemesi enfeksiyon kontrolüne katkı sağlayacaktır.
Etik Kurul Onayı: Necmettin Erbakan Üniversitesi Meram Tıp Fakültesi İlaç ve Tıbbi Cihaz Dışı Araştırmalar Etik Kurulu'nun onayı alınmıştır (22.11.2019/2170).

Çıkar Çatışması: Yazarlar tarafından herhangi bir çıkar çatışması bildirilmemiştir.

Ethics Committee Aproval: This study was carried out with the approval of Necmettin Erbakan University Meram Medical Faculty Medicine and Non-Medical Device Research Ethics Committee (22.11.2019/2170).

Conflict of Interest: No conflict of interest was declared by the authors.

\section{KAYNAKLAR}

1. Ağca $H$, Cilo BD, Özmerdiven $G E$, Sağlam S, Ener B. Candida türlerini tanımlayan bir gerçek zamanlı polimeraz zincir reaksiyonu yönteminin geliştirilmesi. Mikrobiyol Bul. 2015;49(1):56-65. https://doi.org/10.5578/mb.8889

2. Altuncu $E$, Bilgen $H$, Çerikçioğlu $N$, et al. Neonatal kandida enfeksiyonları ve etkenlerinin antifungal duyarlılıkları. Mikrobiyol Bul. 2010;44(4):593-603.

3. Atalay MA, Sav H, Demir G, Koç AN. Kan kültürlerinden izole edilen Candida türlerinin dağılımı ve amfoterisin $B$ ve flukonazole in vitro duyarlılıkları. Selçuk Tıp Derg. 2012;28(3):149-51.

4. Ayhancı T, Altındiş M. Hızla yayılan çoklu ilaca dirençli maya mantarı: Candida auris. Turk Hij Den Biyol Derg. 2020;77(1):123-36. https://doi.org/10.5505/TurkHijyen.2019.26879

5. Bourgeois N, Dehandschoewercker L, Bertout S, Bousquet PJ, Rispail P, Lachaud L. Antifungal susceptibility of 205 Candida spp. isolated primarily during invasive candidiasis and comparison of the Vitek 2 system with the CLSI broth microdilution and Etest methods. J Clin Microbiol. 2010;48(1):154-61. https://doi.org/10.1128/JCM.01096-09

6. Bozkurt-Güzel Ç, Tüysüz M, İnan N, Savage PB. Katyonik steroid antibiyotiklerden olan Csa-8, Csa-13, Csa-44, Csa-131 ve Csa-138'in, kan kültürlerinden izole edilen Candida albicans suşlarına karşı antifungal etkilerinin araştırılması. ANKEM Derg. 2014;28(1): 8-13. https://doi.org/10.5222/ankem.2014.008

7. Clinical and Laboratory Standards Institute (CLSI). Reference method for broth dilution antifungal susceptibility testing of yeasts; fourth informational 
supplement. Wayne: Clinical and Laboratory Standards Institute; 2012 (Document M27-S4).

8. Çalışkan E, Dede A, Biten Güven G. Kan kültürlerinde saptanan Candida türlerinin dağılımı ve antifungal duyarlılıkları. ANKEM Derg. 2013;27(1):25-30. https://doi.org/10.5222/ankem.2013.025

9. Çiçek B, Yılmaz H, Mutlu Yılmaz E, Esen Ş, Birinci A. Candida epidemiyolojisindeki değişikliklerin araştırılması. Mikrobiyol Bul. 2015;49(3):423-31. https://doi.org/10.5578/mb.9647

10. Çiçek-Kolak Ç, Erman-Daloğlu A, Özhak B, Öğünç $D$, Günseren F. Akdeniz Üniversitesi Hastanesi'nde izlenen yetişkin hastalarda kandidemi epidemiyolojisi, Candida türlerinin antifungal duyarlılıkları ve mortalite üzerine etkileri. Klimik Derg. 2019;32(3):250-8. https://doi.org/10.5152/kd.2019.71

11. Dalyan Cilo B, Topaç T, Agca H, Saglam S, Efe K, Ener B. Candida izolatlarinin antifungal duyarlılığının belirlenmesinde Klinik Laboratuvar Standartlari Enstitüsü (CLSI) ve Avrupa Antimikrobiyal Duyarlılık Testleri Komitesi (EUCAST) SIVı mikrodilüsyon yöntemlerinin karşılaştırılması. Mikrobiyol Bul. 2018; 52(1):35-48.

https://doi.org/10.5578/mb.63991

12. Erdem F, Tuncer Erdem G, Oral B, Karakoç E, Demiröz $A P$, Tülek N. Candida türlerine bağlı nozokomiyal enfeksiyonların epidemiyolojik ve mikrobiyolojik açıdan değerlendirilmesi. Mikrobiyol Bul. 2012;46(4):637-48.

13. Etiz P, Kibar F, Ekenoğlu Y, Yaman A. Kan kültürlerinden izole edilen Candida türlerinin dağılımının ve antifungal duyarlılıklarının retrospektif olarak değerlendirilmesi. ANKEM Derg. 2015;29(3):105-13.

14. Falagas ME, Roussos N, Vardakas KZ. Relative frequency of albicans and the various non-albicans Candida spp among candidemia isolates from inpatients in various parts of the world: a systematic review. International Journal of Infectious Diseases. 2010;14(11):e954-e66. https://doi.org/10.1016/j.ijid.2010.04.006

15. Grandesso S, Sapino B, Mazzuccato S, et al. Study on in vitro susceptibility of Candida spp. isolated from blood culture. Le infezioni in medicina: rivista periodica dieziologia, epidemiologia, diagnostica, clinica e terapia delle patologie infettive. SJR. 2012;20(1):2530.

16. Gültekin B, Eyigör M, Tiryaki Y, Kırdar S, Aydın N. Kan kültürlerinden izole edilen Candida suşlarında antifungal duyarlılığın ve bazı virülans faktörlerinin araştırılması ve RAPD-PCR ile genotiplendirilmesi. Mikrobiyol Bul. 2011;45(2):306-17.

17. Hazirolan G, Saribas Z, Arikan Akdagli S. Comparison of microdilution and disk diffusion methods for the detection of fluconazole and voriconazole susceptibility against clinical Candida glabrata isolates and determination of changing susceptibility with new CLSI breakpoints. Mikrobiyol Bul. 2016;50(3): 628-37.

https://doi.org/10.5578/mb.26544

18. Jeffery-Smith A, Taori SK, Schelenz S, et al. Candida auris: a review of the literature. Clin Microbiol Rev. 2018;31(1):e00029-17. https://doi.org/10.1128/CMR.00029-17

19. Jung SI, Shin JH, Song JH, et al and Korean Study Group for Candidemia. Multicenter surveillance of species distribution and antifungal susceptibilities of Candida bloodstream isolates in South Korea. Med Mycol. 2010;48(4):669-74. https://doi.org/10.3109/13693780903410386

20. Karabıçak N, Altun HU, Karatuna O, ve ark. Mikrobiyoloji laboratuvarlarında maya türlerinin tanımlanmasında sık kullanılan ticari sistemlerin değerlendirilmesi: çok merkezli bir çalışma. Mikrobiyol Bul. 2015;49(2):21020. https://doi.org/10.5578/mb.9370

21. Keçeli Özcan S, Mutlu B, Dündar D, Willke A. Kan kültürleinden izole edilen Candida spp. suşlarının antifungal ilaçlara karşı duyarlılıklarının belirlenmesinde buyyon mikrodilüsyon ile $E$ test yöntemlerinin karşılaştırılması. Mikrobiyol Bul. 2010;44(2):263-71.

22. Koçak BY, Kuloğlu F, Çelik AD, Akata $F$. Bir üçüncü basamak hastanesinde erişkin kandidemi olgularının epidemiyolojik özellikleri ve risk faktörlerinin değerlendirilmesi. Mikrobiyol Bul. 2011;45(3):489503.

23. Kooshki P, Rezaei-Matehkolaei A, Mahmoudabadi AZ. The patterns of colonization and antifungal susceptibility of Candida, isolated from preterm neonates in Khorramabad, South West of Iran. J de Mycol Med. 2018;28(2):340-4.

https://doi.org/10.1016/j.mycmed.2018.02.010

24. Maede $Y$, Ibara S, Nagasaki $H$, et al. Micafungin versus fluconazole for prophylaxis against fungal infections in premature infants. Pediatr Int. 2013;55(6):727-30. https://doi.org/10.1111/ped.12157

25. Manzoni P, Wu C, Tweddle L, Roilides E. Micafungin in premature and non-premature infants: a systematic review of 9 clinical trials. The Pediatr Infect Dis J. 2014;33(11):e291. https://doi.org/10.1097/INF.0000000000000434

26. Medrano DJA, Brilhante RSN, Cordeiro RdA, Rocha MFG, Rabenhorst SHB, Sidrim JJC. Candidemia in a Brazilian hospital: the importance of Candida parapsilosis. Rev İnst Med Trop S Paulo. 2006;48(1):1720. https://doi.org/10.1590/S0036-46652006000100004

27. Munoz JF, Gade L, Chow NA, et al. Genomic basis of multidrugresistance, mating, and virulence in Candida auris and related emerging species. bioRxiv. 
2018;299917.

https://doi.org/10.1101/299917

28. Oktay E, Gülbudak H, Özgür D, Otağ F. Yoğun bakım ünitesi hastaları kan kültürlerinden izole edilen Candida parapsilosis suşlarının mini epidemiler bakımından araştırılması. Türk Mikrobiyol Cem Derg. 2015;45(1): 41-7.

https://doi.org/10.5222/TMCD.2015.041

29. Özbek E, Tekay F, Pirinççioğlu HÇ. Yoğun bakım hastalarına ait çeşitli örneklerden izole edilen Candida izolatlarında antifungal direnç. Dicle Tıp Derg. 2012;39(2):207-12.

https://doi.org/10.5798/diclemedj.0921.2012.02.0128

30. Öztürk T, Özseven AG, Çetin ES, Selçuk K. Kan kültürlerinden izole edilen Candida suşlarının tiplendirilmesi ve antifungal duyarlılıklarının araştırılması. Kocatepe Tıp Derg. 2013;14(1):17-22.

31. Pfaller MA, Castanheira M, Messer SA, Moet GJ, Jones $\mathrm{RN}$. Echinocandin and triazole antifungal susceptibility profiles for Candida spp., Cryptococcus neoformans, and Aspergillus fumigatus: application of new CLSI clinical breakpoints and epidemiologic cutoff values to characterize resistance in the Sentry Antimicrobial Surveillance Program (2009). Diagn Microbiol and Infect Dis. 2011;69(1):45-50.

https://doi.org/10.1016/j.diagmicrobio.2010.08.013

32. Rex JH. Clinical and Laboratory Standards Institute. Reference method for broth dilution antifungal susceptibility testing of yeasts: Approved standard M27-A3- 3rd Ed. Wayne, PA: Clinical and Laboratory Standards Institute; (2008).

33. Sardi J, Scorzoni L, Bernardi T, Fusco-Almeida A, Giannini MM. Candida species: current epidemiology, pathogenicity, biofilm formation, natural antifungal products and new therapeutic options. J Med Microbiol. 2013;62(1):10-24.

https://doi.org/10.1099/jmm.0.045054-0

34. Savcı Ü, Yılmaz N. Çeşitli örneklerden izole edilen Candidaların tür dağılımı ve antifungal direnç oranları. Turk J Clin Lab. 2017;8(3):85-90. https://doi.org/10.18663/tjcl.340562

35. Sütçü $M, A$ car $M$, Genç $G E$, ve ark. Pediyatrik invaziv kandidiyazis olgularında Candida türleri'nin ve antifungal duyarlılıklarının değerlendirilmesi. Turk Pediatri Ars. 2017;52(3):145-53.

36. Şahiner F, Ergünay K, Özyurt M, Ardıç N, Hoşbul T,
Haznedaroğlu T. Hastane enfeksiyonu etkeni olarak izole edilen Candida suşlarının genotipik ve fenotipik olarak tanımlanması. Mikrobiyol Bul. 2011;45(3):47888.

37. Temiz H, Temiz S, Kaya Ş. Çeşitli klinik örneklerden izole edilen Kandida türlerinin dağılımı ve antifungal duyarlılıkları. Okmeydanı Tıp Derg. 2015;31(1):13-7. https://doi.org/10.5222/otd.2015.013

38. Tsekoura M, loannidou M, Pana ZD, et al. Efficacy and safety of echinocandins for the treatment of invasive candidiasis in children: a meta-analysis. Pediatr Infect Dis J. 2019;38(1):42-9. https://doi.org/10.1097/INF.0000000000002032

39. Wagener J, Loiko V. Recent insights into the paradoxical effect of echinocandins. Journal of Fungi. 2018;4(1):5. https://doi.org/10.3390/jof4010005

40. Wang $\mathrm{H}$, Xiao $M$, Chen SC-A, et al. In vitro susceptibilities of yeast species to fluconazole and voriconazole as determined by the 2010 National China Hospital Invasive Fungal Surveillance Net study. JCM. 2012;50(12):3952-9. https://doi.org/10.1128/JCM.01130-12

41. Warnock DW. Trends in the epidemiology of invasive fungal infections. Jpn J Med Mycol. 2007;48(1): 1-12. https://doi.org/10.3314/jjmm.48.1

42. Yapar N, Pullukcu H, Avkan-Oguz V, et al. Evaluation of species distribution and risk factors of candidemia: a multicenter case-control study. Med Mycol. 2011;49(1):26-31. https://doi.org/10.3109/13693786.2010.501344

43. Yesil E, Çelebi S, Sezgin Evim M, ve ark. Çocuklarda Mikafungin kullanımının degerlendirilmesi. Mikrobiyol Bul. 2020;54(1):120-34.

44. Yüksekkaya Ş, Fındık D, Arslan U. Yoğun bakım ünitesinde yatan hastaların idrarlarından izole edilen Candida türlerinin moleküler epidemiyolojisi ve antifungal duyarlılıkları. Mikrobiyol Bul. 2011;45(1):137-49.

45. Zhang XB, Yu SJ, Yu JX, Gong YL, Feng W, Sun FJ. Retrospective analysis of epidemiology and prognostic factors for candidemia at a hospital in China, 20002009. Jpn J Infect Dis. 2012;65(6):510-5. https://doi.org/10.7883/yoken.65.510

46. Ziyade N, Elgörmüş N, Arslan MN. Çeşitli Postmortem örneklerden izole edilen maya türlerinin dağılımı ve antifungal duyarlılıkları. Türk Mikrobiyoloji Cem Derg. 2019;49(3):147-53. 